ISSN: 0213-2060

DOI: http://dx.doi.org/10.14201/shhme201533263287

\title{
LOS CONCEJOS DE ZAMORA Y BENAVENTE Y SU RELACIÓN CON LOS CONVENTOS DE LA ORDEN DE PREDICADORES DURANTE LOS SIGLOS XIII-XV
}

\author{
The Councils of Zamora and Benavente and their Relationship with \\ the Order of Preachers Convents during the $13^{\text {th }}-15^{\text {th }}$ Centuries
}

\author{
Alicia ÁLVAREZ RODRÍGUEZ \\ Depto. de Historia Medieval, Moderna y Contemporánea. Facultad de Geografía e Historia. Universidad de \\ Salamanca. C/ Cervantes, s/n. E-37002 Salamanca. C. e.: alicia.al.ro@gmail.com
}

Recibido: 2015-06-10

Revisado: 2015-09-26

Aceptado: 2015-09-28

RESUMEN: A través del presente artículo pretendemos analizar cuál fue la relación que se estableció entre los concejos de Zamora y Benavente y los diferentes conventos masculinos y femeninos pertenecientes a la Orden de Predicadores que se asentaron en dichos ámbitos urbanos. Sirviéndonos de la documentación municipal conservada, y de la propia conventual, examinaremos dicha relación, manifestada a través de diversas facetas, tales como los procesos fundacionales, las ayudas económicas a los conventos, los acontecimientos lúdico-religiosos o la fiscalidad.

Palabras clave: Orden de Predicadores; Dominicos; Convento; Concejo; Zamora; Benavente.

ABSTRACT: With this article we will attempt to analyze which was the relationship between the councils of Zamora and Benavente and the development of the different convents -male and female- of the Order of Preachers, who established themselves in these urban areas. Supporting on the preserved municipal and convents documents, we will examine this 
ALICIA ÁLVAREZ RODRÍGUEZ

LOS CONCEJOS DE ZAMORA Y BENAVENTE Y SU RELACIÓN CON LOS CONVENTOS DE LA ORDEN DE PREDICADORES DURANTE LOS SIGLOS XIII-XV

relationship, shown through several dimensions, such as foundational processes, economic aid to the convents, the recreational and religious events, or taxation.

Keywords: Order of Preachers; Dominicans; Convent; Council; Zamora; Benavente.

SUMARIO: 0 Introducción. 1 La implicación de los órganos concejiles en el asentamiento de los conventos de la Orden de Predicadores en Zamora y Benavente. 2 Los conventos como espacios de reunión concejil. $3 \mathrm{El}$ apoyo material de los concejos a los conventos. 4 Concejos, predicación y educación mendicante. 5 Conventos, concejos y fiscalidad. 6 Concejos y conventos. 7 Referencias bibliográficas.

\section{INTRODUCCIÓN*}

Uno de los aspectos clave que definió la espiritualidad bajomedieval fue el desarrollo y la expansión de las órdenes mendicantes, fenómeno que se originó dentro de los contextos urbanos mediterráneos a principios del siglo XIII ${ }^{1}$. Fueron la Orden de Frailes Menores y la Orden de Predicadores las dos órdenes mendicantes que mayor predicamento obtuvieron dentro de la sociedad europea bajomedieval. De esta manera, las villas y ciudades castellanas iniciaron un proceso de acogida de uno o varios conventos, cuya existencia pronto se convirtió en un elemento más de la estampa urbana medieval. Estas comunidades conventuales, esencialmente urbanas ${ }^{2}$, participaron y se insertaron dentro

\footnotetext{
Abreviaturas: Archivo Histórico Nacional (AHN); Archivo Municipal de Benavente (AMB); Archivo del Monasterio de las Dueñas de Zamora (AMDZ); Archivo Histórico Diocesano de Zamora (AHDZA); Archivo Histórico Provincial de Zamora (AHPZ).

1 El origen de las diferentes órdenes religiosas que pueden ser englobadas dentro del conjunto formado por las órdenes mendicantes se sitúa en distintos puntos del área mediterránea. Así, además de los franciscanos y los dominicos, que constituían las órdenes mendicantes más representativas, también otros grupos religiosos como los carmelitas o los agustinos nacieron en el entorno del Mediterráneo. Fueron los territorios italianos, los condados del sur de Francia, las tierras castellanas y el reino de Jerusalén los espacios geográficos que dieron lugar a las diferentes órdenes mendicantes. Reflexiona sobre estas cuestiones: García SERrano, Francisco. «The Mendicants as a Mediterranean Phenomenon». En Снubb, Taryn E. L. y Kelley, Emily D. (eds.). Mendicants and Merchants in the Medieval Mediterranean. Leiden: Brill, 2013, pp. 272-289.

2 Desde que J. Le Goff evidenciara, allá por los años finales de la década de los sesenta, la conexión existente entre los conventos mendicantes y los entornos urbanos, dicha premisa ha sido mantenida y demostrada por la historiografía posterior, a pesar de las puntualizaciones oportunas que los diferentes historiadores hayan podido realizar sobre este particular, desarrolladas en el caso de la historiografía española, por ejemplo, por José María Miura Andrades. Véase: Le Goff, Jacques. «Apostolat mendiant et fait urbain dans la France médiévale: L'implantation des ordres mendiants. Programme-questionnaire pour une enquête». Annales. Economies, Sociétés, Civilisations, 1968, vol. 23, pp. 335-348; ÍDEM. "Ordres mendiants et urbanisation dans la France médiévale. Etat de l'enquete». Annales. Economies, Sociétés, Civilisations, 1970, vol. 25, pp. 924-946; Miura Andrades, José María. "Las fundaciones de la Orden de Predicadores en el reino de Córdoba. I». Archivo Dominicano, 1988, vol. 9, pp. 343-345. Otra cosa será ya a partir de los siglos xIv y xv, cuando las estrategias señoriales impongan la coexistencia de un nuevo tipo conventual ligado a los ámbitos de seńorío. Sobre este particular, véase, por ejemplo: García Serrano, Francisco. «Del convento al palacio: los frailes y las oligarquías castellanas (siglos XIII-XIV)». En Beceiro Pita, Isabel (dir.). Poder, piedad y devoción. Castilla y su entorno. Siglos XII-XV. Madrid: Sílex, 2014, pp. 77-102.
} 
ALICIA ÁLVAREZ RODRÍGUEZ

LOS CONCEJOS DE ZAMORA Y BENAVENTE Y SU RELACIÓN CON LOS CONVENTOS DE LA ORDEN DE PREDICADORES DURANTE LOS SIGLOS XIII-XV

de los sistemas urbanos que se fueron fraguando a lo largo de los siglos medievales. Así, los conventos de frailes y de monjas jugaron un papel bastante activo, tanto a nivel social como político o económico, dentro del microcosmos urbano, papel que no siempre ha sido atendido por la historiografía española. $Y$ es que no podemos olvidar que las órdenes mendicantes se constituyeron como los nuevos agentes de la espiritualidad bajomedieval $^{3}$, logro obtenido gracias al despliegue de toda una serie de medidas encaminadas a satisfacer las necesidades religiosas de los ambientes urbanos ${ }^{4}$.

Partiendo de la idea de que los concejos castellanos son concebidos como órganos de poder político urbano, nuestro propósito a través del presente trabajo será analizar la actitud exhibida a nivel institucional por los concejos de Zamora y de Benavente, con respecto a los conventos pertenecientes a una de las dos órdenes mendicantes que se instalaron en dichos enclaves urbanos en época medieval. De esta manera, hemos decidido fijar como campo de observación las relaciones que se trabaron entre la Orden de Predicadores, tanto en su vertiente masculina como femenina, y los órganos institucionales concejiles de los dos núcleos urbanos mencionados. Esta relación se hizo visible desde el mismo momento en el que los mendicantes se establecieron en Zamora y en Benavente, allá por el siglo XIII, y la misma se mantuvo a lo largo de toda la baja Edad Media, materializada de diferentes formas, como veremos a continuación. Se trata de un enfoque que hasta el momento no ha sido muy atendido por los historiadores 5 , pero que, sin embargo,

3 La historiografía ha señalado frecuentemente la vinculación que se estableció entre las órdenes mendicantes y los nuevos sectores urbanos que por aquel entonces se hallaban en ebullición, como por ejemplo los mercaderes y los comerciantes. No en vano, serían las órdenes mendicantes las encargadas de habilitar un espacio dentro de la doctrina cristiana para este conjunto de la población, a través de la justificación de las actividades de aquellos que se ganaban la vida mediante profesiones que reportaban beneficios monetarios. Sobre estas cuestiones puede consultarse, por ejemplo: LitTLE, Lester K. Pobreza voluntaria y economía de beneficio. Barcelona: Taurus, 1983, pp. 215-227; AurelL, Jaume. «La espiritualidad de los mercaderes medievales y renacentistas». En Lama, Enrique de la; Merino Rodríguez, Marcelo y Lluch-Baixauli, Miguel. Dos mil años de evangelización: Los grandes ciclos evangelizadores. Pamplona: Servicio de Publicaciones de la Universidad de Navarra, 2001, pp. 99-111.

4 El ars praedicandi difundido por los frailes incluía toda una serie de técnicas encaminadas al ejercicio de la predicación en las que se ponía de manifiesto la nueva cultura urbana. Con los mendicantes se difundieron las predicaciones en lengua vernácula, mucho más accesible para las masas que el latín. De la misma manera, se introdujo la habilidad de predicar mediante el uso de un vocabulario y de una serie de situaciones, a modo de ejemplo, que remitían constantemente a los oficios y costumbres propios de las profesiones urbanas. Este fue un gran acierto, ya que los habitantes de las ciudades hallaron en la espiritualidad ofrecida por los frailes el reflejo de su vida diaria. Los mendicantes, al igual que los comerciantes, utilizaron la palabra, la negociación de la penitencia y la persuasión para atraer a los fieles. Véase: LitTle, Pobreza voluntaria, pp. 243-248.

5 No son muy abundantes los trabajos que aborden este tipo de enfoque dentro de la historiografía castellana, aunque sí es posible enumerar alguno que otro, por ejemplo, José María Miura Andrades analizó la relación que se estableció entre las instituciones civiles locales pertenecientes al reino de Sevilla y los conventos mendicantes allí instalados: Miura ANDRADes, José María. Frailes, monjas y conventos. Las órdenes mendicantes y la sociedad sevillana bajomedieval. Sevilla: Diputación de Sevilla, 1998, pp. 88-117. En cambio, Francisco Javier Rojo Alique centra su perspectiva de análisis en el convento de San Francisco de Valladolid y su interacción con el órgano municipal de la villa: Rojo Alique, Francisco Javier. «El convento de San Francisco de Valladolid en la Edad Media (h. 1220-1518). Vida en el convento y proyección social». Archivo IberoAmericano, 2006, vol. 66, n. ${ }^{\circ}$ 255, pp. 511-519. En otros trabajos sobre los mendicantes o sobre la fiscalidad también se pueden obtener algunas pinceladas sobre esta temática. 
ALICIA ÁLVAREZ RODRÍGUEZ

puede ser útil como vía de análisis, desde otra perspectiva, de la simbiosis que se dio entre los conventos mendicantes y el mundo urbano.

Para afrontar este trabajo hemos recurrido a dos tipos de fuentes. En primer lugar nos hemos servido de la documentación propia de los conventos de la Orden de Predicadores instalados en Zamora y Benavente, la cual se halla distribuida por diferentes archivos. Nuestro segundo tipo de fuente ha sido la documentación emanada de los órganos concejiles. Nos referimos a los Libros de Actas y Acuerdos del concejo y a la documentación municipal de carácter económico. Los fondos municipales conservados son notablemente más abundantes en el caso del concejo benaventano que en el del órgano municipal zamorano. No obstante, la documentación de este tipo que ha llegado hasta nuestros días es bastante escasa, característica que puede ser aplicada también para el conjunto de la documentación conservada proveniente de los fondos municipales de la villa de Benavente. Con respecto a esta última, conocemos algunos Libros de Acuerdos fechados en el año de 1434 y en ciertos años contenidos en las dos últimas décadas del siglo Xv. Igualmente, tan solo han llegado hasta nuestros días algunos de los Libros de Cuentas pertenecientes a los ańos finales del siglo xv. En cuanto al concejo zamorano, solo conocemos los Libros de Acuerdos del concejo pertenecientes a los ańos comprendidos entre 1500 y $1504^{6}$. De la misma manera, no contamos más que con los libramientos procedentes de las Rentas y Bienes de Propios de los años 1484 y 1485.

\section{LA IMPLICACIÓN DE LOS ÓRGANOS CONCEJILES EN EL ASENTAMIENTO DE LOS CON- ventos de la Orden de Predicadores en Zamora y Benavente}

La instalación de los conventos de la Orden de Predicadores en los núcleos urbanos de Zamora y Benavente fue llevada a cabo a lo largo del siglo xiII y a finales de los siglos XIV y XV. Se elevaron un total de cinco complejos conventuales, esto es, dos conventos masculinos y tres femeninos. Como veremos, la intervención de los concejos en los procesos fundacionales de los conventos que se asentaron en Zamora y Benavente puede ser observada sobre todo en el caso de las comunidades masculinas.

Creemos que los frailes pudieron llegar a la ciudad de Zamora de la mano de fray Suero, el primero de los priores provinciales que rigieron la Provincia de Espańa de la Orden de Predicadores ${ }^{7}$. Este hecho acaecería durante los años iniciales de la década de los 20 del siglo XIII, posiblemente a finales de 1221 o principios de $1222^{8}$. A su llegada,

6 Hemos considerado oportuno sobrepasar la frontera imaginaria del 1500 con el fin de incluir en el análisis los primeros Libros de Acuerdos del concejo de Zamora conservados.

7 La división de la Orden de Predicadores en provincias fue una de las medidas que se acordaron en el capítulo general que se celebró en Bolonia en 1221, poco antes del fallecimiento de Domingo de Guzmán. De la misma manera, en esta reunión se creó la figura del prior provincial: VicAIre, Marie-Humbert. Historia de Santo Domingo. Barcelona: Juan Flors, 1964, pp. 568-570.

8 No existe ningún documento en el que se especifique la fecha en la que los frailes dominicos se asentaron en la ciudad de Zamora. Esta circunstancia suele ser bastante habitual en los primeros momentos de expansión de la Orden, en los que los frailes solían arribar de manera espontánea a los núcleos de población, refugiándose en espacios cedidos por los fieles. Después, el paulatino proceso de institucionalización de la 
ALICIA ÁLVAREZ RODRÍGUEZ

LOS CONCEJOS DE ZAMORA Y BENAVENTE Y SU RELACIÓN CON LOS CONVENTOS DE LA ORDEN DE PREDICADORES DURANTE LOS SIGLOS XIII-XV

los frailes procuraron obtener el consentimiento del obispo de la diócesis de Zamora para poder llevar a cabo sus predicaciones dentro de los territorios comprendidos por la misma, tal y como disponían las Constituciones de la Orden de $1220^{9}$. Suero Gómez, junto con otros hermanos de la Orden, se comprometió a obedecer al obispo de Zamora, Martín II, mientras permaneciera en su diócesis. Esta promesa englobaba todos aquellos aspectos que no fueran contrarios a la Orden. Así, en primer lugar, ofrecía la garantía de no recibir diezmos ni primicias, ya que esta posibilidad no estaba permitida, según sus propias Constituciones. Además, los frailes se obligaban a no predicar sin permiso del obispo y solo podrían ofrecer sepultura y confesión a sus propios hermanos. El obispo también se aseguraba de que, si algún otro prior arribara posteriormente a la ciudad de Zamora acompañado de sus hermanos, debería cumplir estas prescripciones, ya que en caso de no ser así, no sería recibido ni por el concilium $^{10}$ ni por él mismo. En efecto, el compromiso de los frailes con el obispo de Zamora ${ }^{11}$ se hacía en presencia del concilium local, institución que se convertía en la principal salvaguarda de los derechos defendidos por el obispo ${ }^{12}$. Los frailes eran acogidos en la ciudad, siempre y cuando cumplieran con estas disposiciones, y el concilium, esto es, el concejo, era testigo de la obediencia prestada

Orden permitiría la habilitación de un protocolo de actuación para la fundación de nuevos conventos. Por lo tanto, las fechas ofrecidas para la llegada de los frailes a la ciudad de Zamora son fruto de un ejercicio de crítica histórica y documental, sostenida a través de un ramillete de referencias y noticias indirectas, fruto de mi tesis doctoral, cuyo título es: Frailes, monjas y mundo urbano: los conventos de la Orden de Predicadores en Zamora, Toro y Benavente en la época medieval.

9 Cum fratres nostri dyocesim alicuius episcopi ad predicandum intraverint, primo si poterunt episcopum illum visitabunt et secundum consilium eius in populo fructum faciant quem facere intendunt et quandiu in eius episcopatu fuerint ipsi in hiis que contra ordinem non fuerint, devote obedientes erunt. Las Constituciones de 1220 de la Orden han sido publicadas en diversas ocasiones. Utilizaremos la versión contenida en la siguiente obra: Gelabert, Miguel; Milagro, José María y Garganta, José María. Santo Domingo de Guzmán visto por sus contemporáneos. Madrid: Editorial Católica, 1947, pp. 785-786.

10 Se suele entender por concilium el conjunto de vecinos -concejo- que formaba parte de la asamblea abierta que solía regir la vida municipal. Se trata de una institución que llegó a su fin cuando a mediados del siglo xIV se instauró el regimiento o concejo cerrado. En la ciudad de Zamora parece que este concejo abierto fue sustituido por otro restringido en 1232, a raíz de una concordia sancionada por Fernando III. Así, el gobierno de la ciudad quedó, desde esa fecha, en manos de 19 jueces: 8 del concejo, 8 de los caballeros, dos del rey y uno del obispo. Posteriormente, en 1342 se implantó el regimiento. A pesar de que el concilium se refería a la reunión abierta de los vecinos, es factible pensar que este sería controlado fundamentalmente por un grupo restringido de los mismos, con toda seguridad aquellos más poderosos: Dios DE Dios, Salustiano de. «Poder político, derecho e instituciones». En Santonja Gómez, Manuel et ál. Historia de Zamora. De los orígenes al final del medievo. Zamora: Instituto de Estudios Zamoranos Florián de Ocampo, Diputación de Zamora, 1995, pp. 670-671; LADERo Quesada, Manuel Fernando. «Zamora, formulación y dinámica del poder en un concejo medieval». Medievalismo. Boletin de la Sociedad Española de Estudios Medievales. 1996, vol. 6, pp. 150-152.

${ }_{11}$ Paul Bertrand también documenta cómo ciertos conventos mendicantes que se instalaron en determinados núcleos urbanos, como Lieja, Brujas, Rodez..., durante la segunda mitad del siglo xiII, debieron acreditar su obediencia ante las instituciones eclesiásticas urbanas antes de asentarse en los mismos: BerTRAND, Paul. «Limitatio, termini, predicatio. Réflexions sur les limites dans les couvents dominicains, entre nord et sud. Autour du dossier documentaire du couvent dominicain de Rodez». En Cahiers de Fanjeaux, 46. Lieux sacrés et espace ecclésial ( $\left(X^{e}-X V^{*}\right.$ siècle). Toulouse: Éditions Privat, 2011, pp. 467-468.

12 ACZ, carp. 13, n.o 24. 1217-1239. Documento también publicado en: Sánchez RodríGueZ, Marciano. Tumbo Blanco de Zamora. Salamanca: [s. n.], 1985, doc. 449. 
ALICIA ÁLVAREZ RODRÍGUEZ

por fray Suero al obispo. De esta manera, podemos reconocer una actitud positiva por parte del concejo con respecto a la instalación de los frailes en la ciudad, aunque las condiciones impuestas por el obispo se convertían en un requisito indispensable que debían cumplir los frailes, y que a su vez era sostenido por el concilium zamorano.

La fundación del convento de Santo Domingo en la villa de Benavente se produjo en la década de los setenta del siglo XIII. La primera noticia de la que disponemos sobre la intención de fundar un convento masculino de la Orden de Predicadores en Benavente es una carta escrita por el concejo de la villa a fray Munio, vicario de los predicadores del reino de León, fechada en diciembre de 1276. En dicho escrito se especificaba que el concejo de Benavente solicitaba que se creara una casa de la Orden de Predicadores en la villa, lo cual se hacía a ruego del infante don Sancho ${ }^{13}$.

Sabemos por las adquisiciones que llevó a cabo la comunidad, con el fin de edificar su morada, que en las inmediaciones de los solares que pasaron a manos de los frailes se localizaba el castillo del concejo $o^{14}$, de cuya función dentro de la villa apenas se sabe nada, aunque, a tenor de su denominación, pudo desempeñar, al menos durante algún tiempo, un papel clave dentro de la vida concejil. No se tiene constancia de cuándo entró en desuso este castillo ${ }^{15}$, aunque en 1397 se le identificaba como castillo viejo en un documento incluido en el libro Becerro del monasterio de Santa Clara de la villa. En cualquier caso, no se trataba del mismo castillo que posteriormente sería utilizado por los Pimentel, cuando fue constituido el condado de Benavente ${ }^{16}$.

Teniendo en cuenta que el concejo de la villa fue uno de los principales responsables de que los frailes acudieran a Benavente, debemos pensar en una cesión por parte del poder municipal de alguna dependencia anexa o próxima al castillo del concejo para que

13 Este documento es conocido gracias a la transcripción que de él hacen los cronistas de la Orden de Predicadores: López, Juan, Tercera parte de la Historia general de Sancto Domingo y de su Orden de Predicadores. Valladolid: por Francisco Fernandez de Cordoua y a su costa, 1613, libro 1, pp. 318-319; Medrano, Manuel José. Historia de la Provincia de España de la Orden de Predicadores. Primera Parte. Progresos de sus fundaciones y vidas de los ilustres hijos, que la ennoblecieron, desde la muerte de su Glorioso Patriarcha, hasta el año de M.CCC. Tomo Segundo. Desde el año de M.C.C.XXI. hasta el fin del siglo XIII. Madrid: por los Herederos de Antonio Gonçalez de Reyes, 1727, p. 608.

14 Johán Bartollamei con otorgamiento de María Pérez, mía muller, vendo a vos, frey Martino prior del monesterio de Santo Domingo de Benavente et al convento de ese mismo logar las casas que yo ey çerca del castiello et de la otra parte enfrontan ena caleya que dizen de don Vidal.

Conosçuda cosa sea a quantos esta carta vierem cómo nos, frey Gómez Pérez, humilloso Maestre de lo que ha la Ordem del Tenple en Leom e en Castiela, ...otorgamos el canbio e confirmamos, que fizo Rodrigo Rodríguez, nuestro Freyre... com los frayres Predicadores moradores en Benavente... um corral que es çerca de las casas de los frayres Predicadores sobredichos, del otro cabo determena el Castiello del conçeyo: Fernández Ruiz, Raquel. Colección diplomática del monasterio de Santo Domingo de Benavente (1228-1390). Benavente: Centro de Estudios Benaventanos Ledo del Pozo, 2000, doc. 10. 1282, enero, 8 y doc. 27. 1298, mayo, 14. Medina del Campo.

15 No se conoce el origen de este castillo, ni su papel dentro del gobierno de la villa. Rafael González Rodríguez se interroga sobre la posibilidad de que el mismo pudiera ser identificado con el castillo de Malgrad -denominación de Benavente antes de ser repoblada en el siglo XII-: González Rodríguez, Rafael. «Notas sobre el llamado "Castillo de Santibáñez" de Benavente». Brigecio. Revista de Estudios de Benavente y sus Tierras, 2004, vol. 14, p. 79. La identificación del castillo como castillo del concejo en un documento nos inclina a pensar que el mismo pudo ser utilizado de alguna forma por el concejo durante algún tiempo, aunque su origen no fuera concejil como tal.

16 González Rodríguez, «Notas sobre el llamado Castillo de Santibáñez», pp. 69 y 78. 
ALICIA ÁLVAREZ RODRÍGUEZ

LOS CONCEJOS DE ZAMORA Y BENAVENTE Y SU RELACIÓN CON LOS CONVENTOS DE LA ORDEN DE PREDICADORES DURANTE LOS SIGLOS XIII-XV

los predicadores se instalaran provisionalmente, mientras se disponía todo lo necesario para la edificación del monasterio ${ }^{17}$. Esta idea se ve reforzada por un documento fechado en 1279 en el que el infante don Sancho se dirigía al concejo en los siguientes términos: Sabades cómmo por mío ruego et por mío mandado diestes a los frayres Predicadores casa ý en vuestro lugar, et ellos, según los sus privillegios, pues que los vos lamastes tomáronla ${ }^{18}$. Posteriormente, las operaciones realizadas por los frailes con el fin de facilitar la construcción del edificio conventual tuvieron como objetivo la apropiación de diferentes casas y corrales situados en las inmediaciones del castillo, como ya hemos señalado.

La posición escogida por los frailes de Santo Domingo para fijar su casa ocupaba un lugar central en el conjunto de la villa, y todo parece indicar que esta ubicación en el corazón de la misma fue facilitada por el concejo benaventano, junto al castillo del concejo. De esta manera, se observa una voluntad por parte de los dominicos, propiciada por el propio poder municipal, de ubicarse en un lugar simbólicamente conectado con el poder concejil $1^{19}$.

No obstante, sería posible intuir, a partir de los documentos otorgados por don Sancho a los frailes en $1277^{20}$ y en 1279 , la existencia de ciertas dificultades que entorpecerían los primeros pasos dados por los dominicos en la villa. La temprana protección ofrecida por don Sancho y la apelación de los frailes al infante, realizada con el fin de obtener el soporte necesario para poder adquirir las propiedades oportunas para elevar su monasterio, así parecen sugerirlo ${ }^{21}$. De hecho, el documento emitido por don Sancho en 1279 fue incluido en una venta realizada en 1282, mediante la cual los frailes pretendían adquirir una pedrera, hecho que puede estarnos indicando la presencia de ciertas dificultades $^{22}$. La inicial instalación de los frailes junto al castillo del concejo y, por consiguiente,

17 Lo habitual era que tras la recepción del proyecto de creación de un nuevo convento por el capítulo provincial, este enviara a un responsable al lugar en cuestión, que se encargaría de las gestiones necesarias para que la inicial instalación transitoria - domus- pudiera ser convertida en un convento aceptado como tal por el capítulo provincial. Reflexionan sobre los procesos de fundación de conventos de la Orden de Predicadores: VICAIRE, Marie Humbert. «Le développement de la Province Dominicaine de Provence (1215-1295)». Annales. Economies, Sociétés, Civilisations, 1973, vol. 28, n.o 4, p. 1019; Miura Andrades, José María. «Las fundaciones dominicas en Andalucía. 1263-1591». En Actas del I Congreso internacional sobre los dominicos y el Nuevo Mundo. Madrid: Deimos, 1988, pp. 78-83.

18 Fernández Ruiz, Colección diplomática del monasterio de Santo Domingo, doc. 8. 1279, febrero, 3. Monteagudo. En este ańo el infante don Sancho se dirigía al concejo con el fin de que este se encargara de gestionar la estimación del precio de las casas o solares que los frailes escogieran para la construcción del monasterio. Los frailes habían transmitido previamente al infante la necesidad de adquirir algunas propiedades, por las que pagarían adecuadamente a sus propietarios, con el fin de elevar el monasterio.

19 En este sentido, Panayota Volti ha documentado cómo algunos conventos franceses y de los Países Bajos se situaron en las cercanías de los lugares de reunión del poder comunal, con frecuencia en las plazas centrales de las villas: Volti, Panayota. Les couvents des ordres mendiants et leur environement à la fin du Moyen Âge. Le nord de la France et les anciens Pays-Bas méridonaux. Paris: CNRS Éditions, 2003, pp. 193-194.

20 En 1277 don Sancho recibe en su guarda y encomienda a los predicadores de Benavente, a su casa y a todas sus cosas: Fernández Ruiz, Colección diplomática del monasterio de Santo Domingo, doc. 6. 1277, marzo, 3. Vitoria.

21 Rafael González Rodríguez también interpreta este hecho en el mismo sentido, considerando que la petición de ayuda al infante estaría relacionada con una insuficiencia de los espacios cedidos a los frailes para elevar el monasterio: GonzÁlez RodríGuez, «Notas sobre el llamado Castillo de Santibáńez», p. 72.

22 Fernández Ruiz, Colección diplomática del monasterio de Santo Domingo, doc. 12. 1282, marzo, 18. 
ALICIA ÁLVAREZ RODRÍGUEZ DE LA ORDEN DE PREDICADORES DURANTE LOS SIGLOS XIII-XV

su necesidad de adquirir solares próximos para construir su monasterio pudo acarrearles ciertos problemas con los propietarios de la zona.

\section{LOS CONVENTOS COMO ESPACIOS DE REUNIÓN CONCEJIL}

Con respecto a la elección de los conventos mendicantes como espacios para la celebración de reuniones concejiles, debemos advertir de que dicha tendencia ha sido documentada de manera más acusada en el caso del convento dominico masculino de Benavente ${ }^{23}$, circunstancia que denota que la conexión entre este convento y el órgano municipal de la villa se fue intensificando con el paso de los ańos.

Esta propensión ha sido reconocida al menos desde el año 1347, fecha a partir de la cual comenzamos a tener constancia de que el interior del convento fue utilizado por el órgano municipal de gobierno como espacio de reunión. Dicha realidad ha sido documentada también para los años 1374 y $1375^{24}$.

Esta situación debió de perpetuarse en el tiempo, ya que en 1397, con motivo de la concesión por parte del concejo de un terreno a los frailes para la construcción de una casa junto a su convento, de la cual precisaban los dominicos, el concejo mencionaba los favores prestados por la comunidad conventual de esta manera:

E por quanto en el dicho monesterio nos fazemos muchos enojos, asy en fazer consestorios commo en otros juntamientos que y fazemos quando es necesario, asy nos el dicho conçejo commo los alcalldes e rregidores del. E por que los frayres que ora y son, commo los que fueron de aqui adelante, sienple sean tenudos de rrogar a dios por la vida e salut de nuestro sennor el rrey, e de nuestra sennora la rreyna, e por prod e bien de nos el dicho conçejo, e por les fazer ayuda e bien damosle el dicho lugar en que fagan la dicha casa ${ }^{25}$.

Así, parece que el recinto conventual serviría al concejo como espacio de reunión con cierta asiduidad, favor que fue adecuadamente premiado por el poder municipal con la concesión del terreno solicitado por los frailes para llevar a cabo la edificación de la

23 Otros autores han mencionado la utilidad de los espacios conventuales masculinos como lugares de reunión concejil. Así, esta realidad ha sido documentada, por ejemplo, por Francisco Javier Rojo Alique para el caso del convento franciscano de la villa de Valladolid: Rojo Alique, "El convento de San Francisco", p. 512; por José María Miura Andrades en los conventos franciscanos y dominicos de Sevilla, Jerez o Écija: Miura Andrades, Frailes, monjas y conventos, pp. 95-96; o por ejemplo, dentro del ámbito catalán, para el caso del convento de San Francisco de Tortosa: Vives i Toro, Eduard. «Els frares menors a les Terres de l'Ebre: el convent de Tortosa (segles XIII-XIV)». Recerca, 2003, vol. 7, p. 255. A nivel europeo, sirva como ejemplo: Freed, John B. The Friars and German Society in the Thirteenth Century. Cambridge: Mediaeval Academy of America, 1977, p. 51.

24 Conocemos estos datos gracias a los diferentes documentos que formaron parte de un pleito que se dirimió entre el concejo de la villa de Benavente y un vecino de la misma: Martínez Sopena, Pascual; Aguado Seisdedos, Vidal y González Rodríguez, Rafael. Privilegios reales de la villa de Benavente (s. XII-XIV). Benavente: Centro de Estudios Benaventanos Ledo del Pozo, 1996, docs. 17 B. 1374; 17 E. 1375, febrero, 9; y 17 I. 1348, mayo, 21. Benavente.

25 AHN, Clero, carp. 3527, n. ${ }^{\circ}$ 7. 1397, mayo, 21. Benavente. Este documento también ha sido publicado por González Rodríguez, «Notas sobre el llamado Castillo de Santibáńez», doc. 3. 
ALICIA ÁLVAREZ RODRÍGUEZ

LOS CONCEJOS DE ZAMORA Y BENAVENTE Y SU RELACIÓN CON LOS CONVENTOS DE LA ORDEN DE PREDICADORES DURANTE LOS SIGLOS XIII-XV

citada casa. A través de esta medida se aprecia la predisposición del órgano municipal para permitir la expansión del espacio conventual a costa de las propiedades municipales. No obstante, este se reservaba el derecho de recuperar los bienes cedidos en caso de que fuera necesario reconstruir la cerca vieja, junto a la cual se localizaba el convento dominico y el terreno que le era entregado por el concejo ${ }^{26}$.

Como se puede apreciar a través de las razones aducidas por el concejo para satisfacer la petición de los frailes, el órgano municipal con esta medida también premiaba la función orante desempeñada por los religiosos por el bien de la monarquía y de la comunidad urbana.

Sin embargo, parece que a los vecinos de la colación de Santibánez, en la cual se localizaba el monasterio, no les parecía buena idea que los frailes construyeran allí dicha casa, ya que, según ellos, a través de las ventanas los frailes tendrían la oportunidad de espiar las actividades desarrolladas por los mismos. Observamos cómo la oposición a esta medida concejil fue ofrecida por la comunidad de vecinos que residía en la citada colación. Finalmente, el concejo permitió a los predicadores la consecución del proyecto, a condición de que estos abrieran las ventanas en el techo de la casa, con el fin de que la vigilancia de los frailes fuera entorpecida. Consideramos que la protesta vecinal en contra de la capacidad de los frailes para abrir ventanas en la nueva casa puede encuadrarse en un contexto más amplio de control por parte de los dominicos de las actividades y del comportamiento desarrollado por la población benaventana. Tendencia, por otra parte, acorde con la esencia predicadora de los frailes dominicos.

A través del Libro de Actas de acuerdos concejiles, conservado para el año de 1434, sabemos que el concejo se reunió dentro del convento prácticamente a lo largo de todo el año, salvo en alguna ocasión en la que los ayuntamientos se desarrollaron en la iglesia de San Nicolás ${ }^{27}$. De nuevo, en los años 1486, 1489 y 1490 volvemos a tener noticias sobre la utilización del monasterio de Santo Domingo como espacio de reunión por el concejo ${ }^{28}$. Durante estos años, en algunas ocasiones, la celebración de las asambleas concejiles transcurrió en el interior de la capilla de Pedro $\mathrm{Coco}^{29}$, regidor y alcalde de la fortaleza de Benavente ${ }^{30}$, o en la del contador y regidor Alonso Martínez $^{31}$, ambas ubicadas dentro del monasterio de Santo Domingo. Tanto Pedro Coco como Alonso Martínez formaban parte del conjunto de servidores que administraban

26 Ya nos hemos referido anteriormente a la localización del convento de Santo Domingo de Benavente en las inmediaciones del castillo del concejo. En este sentido, Rafael González Rodríguez ofrece más detalles en su artículo sobre la cerca vieja del concejo y el castillo del concejo: GonzáLEz RodríGuez, "Notas sobre el llamado Castillo de Santibáńez».

27 AMB, Libro de Actas 4. 1434.

28 AMB, Libros de Actas 2 y 6.

29 AMB, Libro de Actas 2. 1486, noviembre, 3. Benavente; AMB, Libro de Actas 2. 1489, septiembre, 25. Benavente; AMB, Libro de Actas 6. 1490, septiembre, 24. Benavente; AMB, Libro de Actas 6. 1490 , octubre, 3. Benavente.

30 Pedro Coco fundó la capilla de San Antón del convento de Santo Domingo: AHN, Clero, leg. 8196, s/cl. 1487, septiembre, 17. Benavente.

31 AMB, Libro de Actas 2. 1490, agosto, 27. Benavente. Alonso Martínez tenía la capilla de San Andrés del convento dominico: AHN, Clero, leg. 8196, s/cl. 1506, mayo, 12. Benavente. 
ALICIA ÁLVAREZ RODRÍGUEZ

el aparato condal al servicio de los titulares del condado de Benavente, ostentado por los Pimentel ${ }^{32}$.

También el convento de Santo Domingo, de Zamora pudo servir en algún momento como espacio de reunión del concejo de la ciudad. Sin embargo, esta realidad ha sido documentada tan solo en una ocasión, en el ańo 1501, cuando los regidores se reunieron en una capilla del convento ${ }^{33}$. La falta de fuentes concejiles que nos puedan informar sobre este particular nos impide saber si se trató de un hecho puntual o de una costumbre asentada.

\section{EL APOYO MATERIAL DE LOS CONCEJOS A LOS CONVENTOS}

El sustento de tipo económico prestado por los gobiernos municipales a los conventos que se localizaban en las villas y ciudades castellanas se traduce a través de diferentes modalidades, que van desde la entrega directa de una renta fija anual, a la concesión de limosnas y otras mercedes puntuales destinadas a favorecer la realidad material de las comunidades mendicantes. Será dentro del campo económico en el que documentemos, por fin, la presencia de monasterios femeninos dentro del ámbito de actuación del poder municipal en favor de las comunidades conventuales.

Dentro del marco de las asignaciones económicas puntuales se hallan aquellas destinadas a sufragar los gastos derivados de determinadas obras de carácter constructivo o arquitectónico, que fueron llevadas a cabo en varios de los conventos existentes en $\mathrm{Za}$ mora y Benavente. En este sentido, conocemos las actuaciones del concejo de Benavente en favor del convento de Sancti Spíritus de la villa en 1484 y 1485, mediante las cuales se apoyaba económicamente el reparo de una torre, así como las obras de construcción de una tribuna dentro del citado monasterio ${ }^{34}$. De la misma manera, el convento de Santa Catalina de Siena, de Zamora, había recibido la cantidad de 2.000 maravedíes, librados

32 En 1398 la villa de Benavente, tras dos décadas de titubeos, fue definitivamente seńorializada en favor del linaje de los Pimentel, quienes la convirtieron en la cabeza del condado que fue progresivamente configurándose a lo largo de los ańos posteriores. Este condado ha sido estudiado por Isabel Beceiro Pita, quien analiza el organigrama de la administración condal: Beceiro Pita, Isabel. "Caballeros y letrados en las casas señoriales zamoranas del siglo XV». En Primer congreso de historia de Zamora. Zamora: Instituto de Estudios Zamoranos Florián de Ocampo, Diputación de Zamora, 1991, p. 82; Beceiro Pita, Isabel. El condado de Benavente en el siglo XV. Benavente: Centro de Estudios Benaventanos Ledo del Pozo, 1998, pp. 251 y 256; Beceiro Pita, Isabel. «Las redes de la oligarquía en los territorios de seńorío: las élites de Benavente y su entorno». En El condado de Benavente. Relaciones Hispano-Portuguesas en la Baja Edad Media. Actas del Congreso hispano-luso del VI Centenario del Condado de Benavente. Benavente: Centro de Estudios Benaventanos Ledo del Pozo, 2000, pp. 207-208. Igualmente, el funcionamiento del concejo durante el siglo xv, y por tanto su evolución y configuración dentro del marco del poder condal de los Pimentel, ha sido trabajado por: Hernández Vicente, Severiano. El concejo de Benavente en el siglo XV. Zamora: Instituto de Estudios Zamoranos Florián de Ocampo, 1986.

33 Ladero Quesada, Manuel Fernando. Libros de acuerdos del Consistorio de la ciudad de Zamora (1500-1504). Zamora: Excelentísimo Ayuntamiento de Zamora, UNED, 2000, p. 172.

34 Dichos apoyos supusieron las cantidades de 500 maravedíes y de 1.000 maravedíes, respectivamente, los cuales fueron librados por el concejo de la villa en 1484 y 1485: AMB, Cuentas de Propios, leg. 50.7. 1484, mayo, 26. Benavente; AMB, Libro de Actas 2. 1485, abril, 12. Benavente. 
ALICIA ÁLVAREZ RODRÍGUEZ

LOS CONCEJOS DE ZAMORA Y BENAVENTE Y SU RELACIÓN CON LOS CONVENTOS DE LA ORDEN DE PREDICADORES DURANTE LOS SIGLOS XIII-XV

por el concejo zamorano en 1485 , los cuales servirían para la obra de dicho monasterio ${ }^{35}$. En la misma línea se halla el otorgamiento de 2.500 maravedíes realizado por el órgano municipal a favor del convento de Santo Domingo, de Zamora, en 1485, con el fin de que se destinaran a pintar una tribuna de madera para la comunidad ${ }^{36}$.

Por otro lado, los libramientos puntuales en favor de las comunidades conventuales se cifran tanto en cantidades de dinero concretas, a modo de limosna, como en beneficios materiales relacionados con el aprovechamiento de diferentes recursos. Así, los conventos de Santo Domingo, de Santa Catalina de Siena y de Santa María de las Dueñas, de Zamora, fueron favorecidos con diversas limosnas durante los años 1484 y 1485 por el concejo de Zamora $^{37}$. No obstante, hemos de advertir que las comunidades dominicas no fueron las únicas beneficiadas por la política municipal, sino que otros conventos pertenecientes a la Orden de Frailes Menores recibieron varias limosnas durante estos años ${ }^{38}$. Siguiendo esta línea, el convento de Sancti Spíritus, de Benavente, también fue beneficiario de, al menos, dos limosnas de 500 maravedíes cada una durante los años 1485 y $1488^{39}$. De igual manera, la comunidad de Santo Domingo, de Benavente, recibió en 1481 mil maravedíes para que los frailes los destinaran a comprar paño blanco para vestidos ${ }^{40}$.

En cuanto a los beneficios derivados de la explotación de recursos naturales promovidos por el órgano concejil zamorano, podemos identificar en la documentación algunas cesiones puntuales situadas en los aprovechamientos comunales del concejo. Nos referimos a las licencias dadas por el órgano municipal a los conventos de Santo Domingo, las Dueñas y Santa Catalina de Siena, de Zamora, encaminadas al disfrute de varias carretas de leña ${ }^{41}$ y de jara para bardar, durante los años 1500-1504, aunque curiosamente, del

35 Creemos identificar estos 2.000 maravedíes con los 2.000 maravedíes anotados en el Libro de Visitas de la parroquia de Santiago del Burgo, junto a la cual se ubicaba la comunidad conventual y cuya iglesia utilizaba, que fueron otorgados a las monjas para el reparo de la torre de la iglesia por el concejo zamorano antes de 1490: AHDZA, Sec. Archivos Parroquiales, Zamora, Santiago del Burgo, libro 10, fol. 9v.

36 Libramientos con cargo a los ingresos procedentes de las Rentas y Bienes de Propios de la ciudad del año 1485: Ladero Quesada, Manuel Fernando. La ciudad de Zamora en la época de los Reyes Católicos. Economía y gobierno. Zamora: Instituto de Estudios Zamoranos Florián de Ocampo, Diputación de Zamora, 1991, p. 333.

37 En 1484 los conventos de Santo Domingo y de Santa Catalina de Siena recibieron 300 maravedíes de limosna cada uno. En 1485 de nuevo el convento masculino recibió la misma cantidad, mientras que al de las Dueñas fueron otorgados 600 maravedíes, Libramientos con cargo a los ingresos procedentes de las Rentas y Bienes de Propios de la ciudad de los años 1484 y 1485: Ladero Quesada, La ciudad de Zamora, pp. 329-337.

38 El convento de San Francisco de la ciudad recibió 1.300 maravedíes entre los ańos 1484 y 1485 De la misma manera, a la comunidad de Santa Clara le fue otorgada la cantidad de 300 maravedíes en 1484 , Libramientos con cargo a los ingresos procedentes de las Rentas y Bienes de Propios de la ciudad de los ańos 1484 y 1485: LAdero Quesada, La ciudad de Zamora, pp. 329-337. No se documentan limosnas ni libramientos durante estos ańos a otros monasterios existentes en la ciudad, no pertenecientes a las órdenes mendicantes, como el de San Benito.

39 AMB, Libro de Actas 2. 1485, marzo, 11. Benavente; AMB, Libro de Actas 2. 1488, febrero, 27. Benavente.

40 AMB, Libro de Actas 1. 1481, junio, 13. Benavente.

41 En 1500 solo recibieron leńa las comunidades franciscanas de Santa Clara y de San Francisco, actividad que, al parecer, solía acostumbrarse: LADERo Quesada, Libros de acuerdos, p. 100. En 1502 las afortunadas fueron las comunidades de Santo Domingo, las Dueńas y San Francisco, mientras que en 1404 el concejo emitió un acuerdo general sobre la entrega de leña a los monasterios de la ciudad: LADERo QUESADA, Libros de acuerdos, pp. 223, 225, 228 y 376. 
ALICIA ÁLVAREZ RODRÍGUEZ

aprovechamiento de la jara solo se beneficiarían los conventos femeninos ${ }^{42}$. Igualmente, dicha merced fue reconocida también para los conventos de la Orden de Frailes Menores.

Con respecto al establecimiento de una renta fija destinada a favorecer la situación económica de los conventos, debemos referirnos al disfrute de la martiniega por parte del convento de Santo Domingo, de Zamora. Una porción de dicha renta -144 maravedíesfue cedida por el monarca Alfonso IX a la comunidad de frailes poco después de que estos se instalaran en la ciudad de Zamora. Dicha merced se hacía con la intención de que esta cantidad de dinero fuera empleada para el vestuario de la comunidad ${ }^{43}$. En un momento indeterminado, posterior al año 1347, la percepción de esta renta debió de ser transferida por el monarca en favor del concejo zamorano ${ }^{44}$. Sin embargo, este siempre mantuvo la obligación de respetar el citado privilegio de la comunidad dominica. De hecho, en una de las ordenanzas de la ciudad, en la que se regulaba el arrendamiento de la renta de la martiniega, se especificaba claramente que el arrendador de la mima debía comprometerse a respetar la porción de renta correspondiente a los dominicos, asumiendo la entera responsabilidad de pagársela de la misma manera que hasta ese momento lo había hecho la ciudad ${ }^{45}$.

En el caso del convento de Santo Domingo, de Benavente, es posible apreciar una clara intención por parte del órgano concejil de asignarle una renta fija de las pertenecientes al ámbito de la fiscalidad urbana. Así, en 1464 el concejo de la villa cedía a la comunidad dominica benaventana la cantidad de 2.000 maravedíes situados en la renta del peso de buhonería, como recompensa por todos los beneficios y favores prestados por la misma al concejo de la villa ${ }^{46}$. Esta merced será analizada a continuación.

\section{CONCEJOS, PREDICACIÓN Y EDUCACIÓN MENDICANTE}

Desde el punto de vista institucional, los concejos también desempeñaron una función como garantes de la labor realizada por los predicadores entre la población. Fue a lo

42 En 1501 el convento de Santiago del Burgo (Santa Catalina de Siena) recibía 50 cargas de jara para bardar provenientes del monte del concejo. En 1502 fueron los monasterios de las Dueñas y de Santa Clara los que fueron premiados con cargas de jara, mientras que en 1503 de nuevo las Dueñas recibieron esta merced: Ladero Quesada, Libros de acuerdos, pp. 184, 224, 228 y 336.

43 Existe una carta de confirmación al convento zamorano del privilegio de la renta de la martiniega, expedida por el rey Alfonso XI, en la que se menciona que dicha merced proviene del monarca Alfonso IX: AHPZ, leg. 1117, no 2. 1347, abril, 10. Illescas.

44 Sabemos que dicha cesión debió de realizarse después de 1347, porque en el privilegio confirmado por el rey Alfonso XI, anteriormente mencionado, este monarca se refería a la recepción de la renta de la martiniega, todavía en sus manos. No obstante, la transferencia de rentas de derecho regio a las haciendas municipales, en proceso de construcción, constituyó una tendencia bastante habitual que contribuyó a facilitar dicho proceso. Para obtener una visión mayor sobre el funcionamiento de la fiscalidad real y de la fiscalidad municipal, puede consultarse: LADERo Quesada, Miguel Ángel. Fiscalidad y poder real en Castilla. Madrid: Editorial Complutense, 1993; y Finanzas y fiscalidad municipal. V Congreso de Estudios Medievales. [Ávila]: Fundación Sánchez-Albornoz, 1997.

45 Las ordenanzas de la ciudad de Zamora han sido publicadas por: CANTo de la Fuente, Carlos del; Carbajo Martín, Victoriano Antonio y Moreta Velayos, Salustiano. Ordenanzas municipales de Zamora: siglos XV y XVI. Zamora: Diputación Provincial de Zamora, 1991.

${ }^{46}$ AHN, Clero, carp. 3.532, n. ${ }^{\circ} 16.1464$, febrero, 16 . Benavente. 
ALICIA ÁLVAREZ RODRÍGUEZ

LOS CONCEJOS DE ZAMORA Y BENAVENTE Y SU RELACIÓN CON LOS CONVENTOS DE LA ORDEN DE PREDICADORES DURANTE LOS SIGLOS XIII-XV

largo del siglo XV, sobre todo, cuando se intensificó la costumbre de que los predicadores viajaran por las diferentes villas y ciudades con el fin de extender sus sermones a los habitantes de las mismas. Uno de los predicadores más famosos, que desarrolló su actividad durante la segunda mitad del siglo xIV y las primeras décadas del siglo Xv, fue San Vicente Ferrer ${ }^{47}$, fraile dominico que propagó sus sermones, no solo por toda la Península Ibérica, sino también por varios reinos europeos. De esta manera, desde finales del siglo XIV y a lo largo de todo el siglo xv, la incidencia de los predicadores en las mentalidades populares tuvo una gran importancia, dentro de un contexto de tipo reformista, cuyas ideas serían asumidas por la sociedad al completo ${ }^{48}$.

Hervé Martin aborda en varios de sus estudios el trabajo desempeñado por los predicadores profesionales que desarrollaban sus predicaciones en el ámbito francés medieval. Documenta cómo la función de los predicadores fue progresivamente profesionalizada, hasta el punto de que las villas y ciudades francesas, a partir de la segunda mitad del siglo xv, comenzaron a registrar en sus contabilidades una serie de retribuciones regulares destinadas a pagar los salarios de los predicadores. De esta manera, su misión dentro del microcosmos urbano también fue valorada como uno de los servicios necesarios que las instituciones de gobierno urbano debían ofrecer y asegurar al conjunto de la población ${ }^{49}$.

Siguiendo esta línea, el concejo de Zamora efectuó varios libramientos en favor de algunos frailes del convento de Santo Domingo con el fin de pagar el salario que les correspondía por su labor como predicadores ${ }^{50}$. En ellos se remuneraban los servicios prestados por fray Antón y por fray Juan de Santo Domingo en favor de la comunidad

47 La bibliografía existente sobre este predicador es muy extensa. Por ejemplo, se puede mencionar: Cátedra García, Pedro M. Sermón, sociedad y literatura en la Edad Media: San Vicente Ferrer en Castilla (1411-1412). Valladolid: Junta de Castilla y León, 1994; Вешснот, Mauricio. Pensamiento filosófico de San Vicente Ferrer. València: Ajuntament de València, 1995; Mira, Joan F. San Vicente Ferrer: vida y leyenda de un predicador. Alzira: Algar, 2002.

48 Rucquor, Adeline. «La réforme monastique en Castille au Xve siècle: une affaire sociale». En DuBoIs, Henri y VAuCHez, André. Horizons marins, itinéraires spirituels. Hommage au professeur Michel Mollat. Paris: Publications de la Sorbonne, 1987, vol. 1, pp. 243-246.

49 Martin, Hervé. «La prédication comme travail reconnu et rétribué à la fin du Moyen Âge». En Hamesse, Jacqueline y Muaille-Samaran, Colette (eds.). Le travail au Moyen Âge. Une approche interdisciplinaire. Actes du Colloque international de Louvain-la-Neuve. Louvain-la-Neuve: Université Catholique de Louvain, 1990, pp. 396-400; ÍDEM. Le metier de prédicateur à la fin du Moyen Âge (1350-1520). Paris: Éditions du Cerf, 2007, pp. 146-189.

50 Esta preocupación del órgano concejil por remunerar el servicio prestado por los predicadores está documentada en otras villas y ciudades peninsulares. Por ejemplo, así ocurría en la villa de Haro, donde los frailes franciscanos, provenientes de otras villas cercanas, se encaminaban a la misma para predicar. Los gastos de alojamiento y salarios de los predicadores eran pagados por las arcas municipales: Goicolea Julí́N, Francisco Javier. «La influencia de las órdenes mendicantes en la religiosidad de los fieles de la villa de Haro a finales de la Edad Media». En Iglesia DuARTe, José Ignacio de la (coord.). Espiritualidad, órdenes mendicantes y franciscanismo en la baja Edad Media. VI Semana de Estudios Medievales de Nájera. Logroño: Instituto de Estudios Riojanos, 1996, pp. 260-261. Igualmente, esta actividad es mencionada para el concejo madrileńo por Graña Cid, María del Mar. «Frailes, predicación y caminos en Madrid. Un modelo para estudiar la itinerancia mendicante en la Edad Media». En Segura Graíño, Cristina (ed.). Caminos y caminantes por las tierras de Madrid. Madrid: Asociación Cultural Al-Mudayna, 1994, pp. 300-301. 
ALICIA ÁLVAREZ RODRÍGUEZ

urbana por predicar la palabra de $\operatorname{Dios}^{51}$. Curiosamente, tanto en el año 1484 como en el de 1485 no se documenta ningún otro libramiento por parte del concejo a ningún fraile perteneciente a otra orden, en concreto a ningún fraile franciscano ${ }^{52}$. Esta circunstancia nos informa sobre la preferencia, al menos para estos ańos, del órgano concejil por la actividad predicadora de los dominicos.

Esta predilección del concejo zamorano por los frailes pertenecientes a la Orden de Predicadores, al menos en los años de los que tenemos noticia, para cubrir las necesidades espirituales de la población también fue una elección compartida por el órgano de gobierno municipal benaventano. Nos referimos a la participación de los dominicos de Benavente en la fiesta del Corpus Christi. Este festejo suponía una de las fiestas cívicas más importante de las ciudades y villas en la baja Edad Media. A través de la misma se conmemoraba el triunfo de la gracia y de la Eucaristía, como símbolo del cristianismo ${ }^{53}$. Este tipo de festejos servían para aglutinar a la comunidad urbana, y los mismos eran contemplados por los habitantes de los núcleos urbanos, quienes podían participar en ellos de diversas formas. En el caso benaventano, según refiere Isabel Beceiro Pita, parece que era el propio concejo el órgano institucional que se encargaba de la financiación de la fiesta, en cuyo desarrollo los frailes dominicos participaban con su presencia en el desfile procesional, y mediante la organización de unos juegos, en los que se solían llevar a cabo diferentes representaciones alegóricas ${ }^{54}$. La importancia de la contribución del convento dominicano a la fiesta del Corpus reside en que era la única institución religiosa de la villa que aparece documentada interviniendo activamente en la organización de los citados festejos. La participación del convento de Santo Domingo en el desarrollo de los citados juegos parece ser anterior a la década de 1480, según interpreta Beceiro Pita ${ }^{55}$. Hay

51 Libramientos con cargo a los ingresos procedentes de las Rentas y Bienes de Propios de la ciudad del año 1484 y 1485: LADERo Quesada, La ciudad de Zamora, pp. 331 y 334.

52 Nos referimos a que explícitamente no se indica que las limosnas recibidas por el convento de San Francisco sean fruto del pago de los servicios prestados por los frailes como predicadores, aunque sí se documenten limosnas efectuadas por el concejo al convento franciscano, como ya hemos señalado. Por esta razón, consideramos que, al menos durante estos años, el cumplimiento de la función de predicadores por parte de los dominicos fue llevada a cabo de manera exclusiva.

53 Beceiro Pita, Isabel. «La intervención de la autoridad en las celebraciones religiosas: las fiestas de Benavente y su tierra (1434-1525)». Edad Media. Revista de Historia, 2009, vol. 10, pp. 212-213. Sobre la fiesta del Corpus y otros festejos relacionados con el mundo urbano castellano puede consultarse, por ejemplo: Asenjo GonzÁLez, María. "Fiestas y celebraciones en las ciudades castellanas de la Baja Edad Media». Edad Media. Revista de Historia, 2013, vol. 14, pp. 35-61.

54 Beceiro Pita, «La intervención de la autoridad», pp. 204 y 206. En los libros donde se anotaba la contabilidad del concejo se consignaban también los gastos derivados de la celebración de la fiesta del Corpus, los cuales eran sufragados por el órgano concejil. Con frecuencia, se trata de apuntes en los que se dejaba constancia del destino detallado del dinero que era empleado para la organización de la fiesta. En varias ocasiones se mencionaban partidas de material para los juegos de Santo Domingo. Por ejemplo, en 1487 observamos cómo el concejo destinaba 18 maravedíes para comprar 275 tachuelas que serían empleadas en los caballicos y otros menesteres de los juegos de Santo Domingo. Igualmente, ese mismo año se empleaban 59 maravedíes para pagar cuatro pares de guantes y 100 alfileres de los juegos de Santo Domingo: AMB, Cuentas de Propios, leg. 23.1. 1487. Benavente. Otras alusiones a gastos relacionados con el convento en: AMB, Cuentas de Propios, leg. 50.8. 1491; AMB, Cuentas de Propios, leg. 50.6. 1482, agosto, 21. Benavente.

55 Beceiro Pita, «La intervención de la autoridad», p. 206. 
ALICIA ÁLVAREZ RODRÍGUEZ

LOS CONCEJOS DE ZAMORA Y BENAVENTE Y SU RELACIÓN CON LOS CONVENTOS DE LA ORDEN DE PREDICADORES DURANTE LOS SIGLOS XIII-XV

que tener en cuenta, que la fiesta del Corpus Christi representaba para los frailes dominicos la mejor de las ocasiones posibles para poner en práctica una de las actividades que más acertadamente definían su función dentro de la sociedad. Y es que, con motivo de la celebración de esta procesión, las oportunidades para catequizar a la sociedad mediante diferentes representaciones teatrales en las que se exponían determinadas escenas bíblicas e historias, y donde los personajes alegóricos desempeñaban un papel destacado, eran inmejorables.

Por otro lado, la implicación de los frailes dominicos en la procesión del Corpus era expresada de esta manera por el concejo:

Otrosý, por quel dicho prior e frayres del dicho monesterio, por honrrar la fiesta del día de Corpus Christi de cada año, van con sus cruzes e cáliçes e ornamentos e conçiertos santos del dicho monesterio, lo más honrradamente que pueden, a su costa e misyón, en que gastan asaz quantía de maravedíes ${ }^{56}$.

Dicha colaboración fue adecuadamente premiada, mediante la asignación de 2.000 maravedíes anuales, situados en la renta del peso de buhonería, como señalamos anteriormente $^{57}$. Sin embargo, la gratificación del órgano municipal, expresada a través de la citada cantidad monetaria, también respondía al agradecimiento que el concejo sentía hacia los frailes por los muchos servicios prestados por estos, los cuales eran resumidos de esta manera:

Otorgamos e conosçemos que por quanto a nuestra notiçia es venida que nuestros antesçesores syempre huvieron muchos cargos de los frayres religiosos que fueron e han seýdo del monesterio de Santo Domingo de la dicha villa, por las muchas honrras e benefiçios que dellos han rresçebido en los sus santos sacrefiçios e oraçiones, et nosotros tenemos en memoria, desde el tiempo que somos justiçia e rregidores de la dicha villa, que somos ayudados e honrrados dellos en lo susodicho, et los avemos prestos para todas las cosas que de cada día las avemos nesçesarios en sus santos sacrefiçios e oraciones, et avemos sabido que fasta aquí los dichos nuestros antesçesores non les han rrespondido con aquellas limosnas que de rrazón les devieran rresponder $^{58}$.

Sin embargo, parece que no todos los ańos los frailes de Santo Domingo se encargaron de organizar los juegos. No sabemos a qué se debió esta ausencia, pero lo cierto es que en 1483 los frailes no recibieron 500 maravedíes del total de los 2.000 que tenían asignados por el concejo. La razón fue que el convento no había cumplido con su costumbre de hacer los juegos el día del Corpus Christi ${ }^{59}$.

De nuevo se aprecia un sentimiento de gratitud por parte del órgano municipal, amparado en la función orante desempeńada por los frailes por el conjunto de los regidores benaventanos.

56 AHN, Clero, carp. 3.532, n. ${ }^{\circ} 16.1464$, febrero, 16. Benavente.

57 AHN, Clero, carp. 3.532, n. ${ }^{\circ} 16.1464$, febrero, 16. Benavente.

58 AHN, Clero, carp. 3.532, n. ${ }^{\circ} 16.1464$, febrero, 16. Benavente.

59 AMB, Cuentas de Propios, leg. 50.6. 1483. Benavente. 
ALICIA ÁLVAREZ RODRÍGUEZ

Por otro lado, el convento de Santo Domingo, de Benavente, además, cumpliría una función educativa dentro de la villa. Dicha comunidad, y más concretamente fray Pedro de Castroverde, recibiría 3.000 maravedíes anuales sufragados por el concejo, con el fin de que fueran impartidas clases de gramática en el convento a todos los que las quisieran oír. Este acuerdo se llevó a cabo en $1470^{60}$. En 1487 el mismo órgano concejil intervenía en la construcción de un Estudio dentro del convento de Santo Domingo, dato que conocemos gracias a los gastos que se derivaron de dicha edificación, los cuales fueron consignados en los Libros de Actas del concejo ${ }^{61}$. Sin embargo, esta no fue la única comunidad que gozó del favor concejil a la hora de subvencionar determinados gastos relacionados con el estudio. El convento de San Francisco de la villa también contó con el apoyo concejil para el levantamiento de un Estudio dentro del mismo ${ }^{62}$.

\section{Conventos, CONCEJOS Y FISCALIDAD}

La fiscalidad en época medieval constituía un elemento de suma importancia que afectaba al conjunto de los habitantes del reino y, por supuesto, a los núcleos urbanos. Las frecuentes condiciones de exención de los vasallos conventuales, así como su habitual capacidad para percibir situados en determinadas rentas, suscitaron algunos problemas dentro del marco concejil, que analizaremos a continuación.

Ya nos hemos referido anteriormente a la facultad que tenía el convento de Santo Domingo, de Zamora, de disfrutar de cierta cantidad de maravedíes situados en la renta de la martiniega. En 1347 el monarca Alfonso XI defendía el derecho de percepción del convento de los 864 maravedíes que le correspondían en la martiniega de la ciudad. Dicha defensa era necesaria ante las quejas enarboladas por los cogedores de la renta, quienes argumentaban sobre la imposibilidad de acudir al mismo con la cantidad requerida, debido a que los pechos recogidos en la tierra no eran suficientes para satisfacer el monto total de los maravedíes que correspondían al convento, lo que repercutía negativamente en el resto de los vasallos, quienes se veían obligados a incrementar sus contribuciones para satisfacerla. El monarca se decantó a favor de la comunidad dominica ${ }^{63}$.

Varias décadas más tarde, los problemas derivados del abono de la renta al convento desembocaron en lo que parece presentarse como un nuevo conflicto con el concejo. Lo cierto es que no poseemos muchos detalles que ilustren este asunto, pero sabemos que en 1378 el juez de la ciudad condenó al cogedor de la martiniega a pagar al convento

60 AMB, Libro de Actas 6. 1470, agosto, 3. Benavente. A finales del siglo xvi se produjo la fundación de una cátedra de gramática en la villa de Benavente, protagonizada por Alonso de Carvajal y en la que también estaría implicado el órgano concejil. Sobre esta cuestión puede consultarse: RebordinOs Hernando, Francisco José. La cátedra de gramática de Benavente (1589-1845). Benavente: Ayuntamiento de Benavente, 2010.

61 AMB, Cuentas de Propios, leg. 23.1. 1487. Benavente.

62 AMB, Libro de Actas 6. 1489, julio, 24. Benavente; AMB, Libro de Actas 6. 1490, octubre, 5. Benavente; AMB, Libro de Actas 6. 1490, noviembre, 6. Benavente.

63 AHPZ, leg. 1.117, n. ${ }^{\circ}$ 2. 1347, abril, 10. Illescas. 
ALICIA ÁLVAREZ RODRÍGUEZ

LOS CONCEJOS DE ZAMORA Y BENAVENTE Y SU RELACIÓN CON LOS CONVENTOS DE LA ORDEN DE PREDICADORES DURANTE LOS SIGLOS XIII-XV

1.728 maravedíes, suponemos que porque este se habría negado anteriormente a respetar dicho privilegio ${ }^{64}$.

También el convento de Santo Domingo, de Benavente, debió de enfrentarse a ciertos problemas relacionados con la fiscalidad. En este caso, el conflicto surgió porque los cogedores de las rentas regias no respetaron el derecho a los dos excusados que tenía la comunidad dominica. De esta manera, a Marcos Pérez, pellitero y excusado del convento, le habían requisado algunos pellotes en prenda por la cantidad de dinero que, según los cogedores, debía por el pago de la fonsadera regia, la cual dichos excusados estaban exentos de pagar. El alcalde de Benavente dicto una sentencia favorable al convento, reconociendo el derecho del excusado de la comunidad ${ }^{65}$.

Pero no solo los concejos chocaron con los conventos masculinos en cuestiones relativas a la fiscalidad, sino que también el monasterio de Santa María de las Dueñas, de Zamora, sufrió este tipo de contrariedades. En 1311 Fernando IV se dirigía a los jueces y alcaldes de la ciudad a fin de que los sacadores de las rentas respetaran el privilegio del que disfrutaban las monjas de excusar a sus vasallos, el cual había sido otorgado por Sancho IV en $1290^{66}$. Esta advertencia nos está indicando que dentro del ámbito de la recaudación concejil de las rentas reales no se estaba respetando el privilegio obtenido por las dominicas. Cuatro años más tarde, dicha carta era confirmada por Alfonso $\mathrm{XI}^{67}$. Lógicamente, la existencia de excusados, que no contribuían a satisfacer el monto de las rentas debidas, repercutía negativamente en el resto de la población, que tenía que asumir las cantidades excusadas por los vasallos de las monjas. Esta misma situación parece reiterarse en 1409, cuando Juan II decidió limitar los excusados de las religiosas a 8, ante la petición de las mismas al monarca de una solución que pusiera punto y final al incumplimiento de sus privilegios por parte de los recaudadores ${ }^{68}$.

En 1322 se produjo otro sonado conflicto entre el monasterio de las Dueńas y el concejo a consecuencia de la soldada del juez de salario zamorano. Así, Fernando Domínguez Paniagua había decidido obligar a los vasallos de las religiosas a contribuir con la soldada debida por el rey al juez, Pedro González de Salamanca. Esta situación había provocado que las monjas protestaran enérgicamente, a través de sus procuradores, siguiéndose un largo pleito que había provocado que el conjunto de los caballeros y hombres buenos de la ciudad de Zamora salieran en defensa de los derechos de las dominicas. Los argumentos a favor de las monjas residían en que se trataba de un monasterio compuesto por hijas de hidalgos, de caballeros y de hombres buenos de la ciudad de Zamora

64 AHPZ, Desamortización, libro 1, fol. 67r. Se documenta algún que otro conflicto, de índole similar, entre el órgano concejil y otro tipo de privilegiados, a los que también les correspondía un situado en las martiniegas por merced regia. Este fue el caso de Pedro Yánez, quien recibió de la reina Catalina las martiniegas de Zamora por juro de heredad, lo que desembocó en un pleito entre el mismo y los regidores del concejo, que se prolongó durante los años 1413-1416, y que finalmente obligó al concejo a pagar anualmente 400 florines a Pedro Yáńez: Ladero Quesada, La ciudad de Zamora, pp. 234-235.

65 Fernández Ruiz, Colección diplomática del monasterio de Santo Domingo, doc. 47. 1357, junio, 28. Benavente.

66 AMDZ, carp. privilegios, n. ${ }^{\circ} 2.1290$, agosto, 20. Huete.

${ }^{67}$ AMDZ, carp. 2, n. ${ }^{\circ} 13.1315$, octubre, 7. Burgos.

68 AMDZ, carp. 2, n. ${ }^{\circ} 11.1409$, junio, 7. 
ALICIA ÁLVAREZ RODRÍGUEZ

y de otros lugares próximos, como Salamanca o Toro, los cuales estaban exentos de la citada contribución. De la misma manera, los vasallos de las monjas nunca antes habían pagado la soldada del juez de salario y, por otro lado, sus bienes eran de realengo y no de abadengo, por lo que sus vasallos y merinos no estaban obligados a satisfacer dichos pechos ${ }^{69}$. Finalmente, el alcalde Domingo González sentenció el pleito a favor de las monjas, reconociendo el derecho de las mismas a que sus vasallos y merinos no pagaran la soldada del juez de salario ${ }^{70}$.

Lo cierto es que la contraposición entre los derechos concejiles y los derechos eclesiásticos fue una cuestión que acarreó numerosas dificultades a nivel general del reino. Fueron frecuentes las quejas enarboladas por los concejos en defensa del realengo, frente a la amenaza que suponía la extensión del abadengo dentro de sus territorios, y en consecuencia como expresión de la defensa de sus derechos, los cuales se hallaban en proceso de ascensión ${ }^{71}$. Sin embargo, se puede apreciar cómo a raíz del desarrollo de este pleito la comunidad de caballeros, hidalgos y hombres buenos de la ciudad de Zamora sostuvo la defensa de los derechos de las monjas, quienes, por otro lado, mantenían relaciones de parentesco con los mismos. La figura del juez de salario fue una medida introducida por la monarquía dentro de los concejos con el fin de incrementar su capacidad de control sobre los mismos, por lo que en ocasiones su presencia desembocó en ciertos problemas, atestiguados también en otros ámbitos concejiles, como por ejemplo el de Benavente ${ }^{72}$. Su mantenimiento era costoso para el conjunto de los pecheros y, además, solía tratarse de una persona extraña al marco urbano, razones que por sí mismas podrían explicar la férrea defensa mantenida por el conjunto de los caballeros, hidalgos y hombres buenos que formaban parte de la comunidad urbana en favor de las monjas, los cuales posiblemente,

69 En torno a 1278 se produjo un pleito entre el cabildo de Zamora y el concejo de la ciudad, a consecuencia de la supresión por parte del segundo del juez eclesiástico al que tenía derecho la Iglesia, gracias a la concordia dictada por el rey Fernando III en 1232, y a la cual ya nos hemos referido anteriormente. Dicha eliminación se concretaba a raíz de la introducción del juez de salario en el marco del gobierno municipal, ocasión que fue aprovechada por el concejo para acabar con el citado derecho eclesiástico. El enfrentamiento entre el concejo y la Iglesia de Zamora se producía dentro de un contexto de oposición generalizada entre ambos poderes por el control del territorio zamorano, el cual dio lugar a otro tipo de pleitos y conflictos. Sobre este particular, véase: DíAZ IBÁŃEZ, Jorge. «Monarquía, Iglesia y poder concejil en Zamora durante la baja Edad Media. Análisis tipológico de los conflictos». Anuario del Instituto de Estudios Zamoranos Florián de Ocampo, 2004, vol. 21, pp. 241-253. Una de las cuestiones que fueron disputadas era precisamente la contribución de los vasallos de la Iglesia al pago de la soldada del juez de salario, petición que era reclamada por el órgano concejil. Sin embargo, Sancho IV se mostró favorable a los requerimientos eclesiásticos, CoRIA Colino, Jesús. «El pleito entre el cabildo y concejo zamoranos de 1278: análisis de la conflictividad jurisdiccional. Concejo, cabildo y rey». En Primer Congreso de Historia de Zamora. Zamora: Instituto de Estudios Zamoranos Florián de Ocampo, Diputación de Zamora, 1991, pp. 285-303.

70 AMDZ, carp. 2, n. ${ }^{\circ}$ 9. 1322, noviembre, 10. Zamora.

71 Sobre esta cuestión puede verse, por ejemplo: Nieto Soria, José Manuel. «Abadengo episcopal y realengo en tiempos de Alfonso XI de Castilla». En la España medieval, 1984, vol. 4, pp. 707-734; ARRANZ GuzMán, Ana. "El tercer estado castellano ante las relaciones realengo-abadengo: siglos XIII-XV». Hispania, 1989, vol. 49, n. ${ }^{\circ} 172$, pp. 443-476.

72 Maceda Cortés, María Luisa. «El concejo de Benavente de los siglos XII al XIV». En la España medieval, 1984, vol. 4, p. 588; GonZález Ramos, José Ignacio. Villas reales en el reino de León. Los procesos pobladores de Fernando II y Alfonso IX en la Tierra de León. León: Centro de Estudios e Investigación San Isidoro, 2008, pp. 95-96 y 100. 
ALICIA ÁLVAREZ RODRÍGUEZ

LOS CONCEJOS DE ZAMORA Y BENAVENTE Y SU RELACIÓN CON LOS CONVENTOS DE LA ORDEN DE PREDICADORES DURANTE LOS SIGLOS XIII-XV

por otro lado, detentaran el poder concejil. Además, no lo olvidemos, se trataba de mujeres vinculadas con ellos mediante relaciones de parentesco.

Pero los problemas de las Dueñas a consecuencia de la recaudación fiscal no cesaron aquí. En 1467 Enrique IV dirigía una carta al concejo de Zamora, y a sus recaudadores, para que velaran por el derecho de las monjas a recibir las 40 cargas de trigo y los 2.000 maravedíes que las mismas tenían situados en la alcabala de la paja y de la leńa de la ciudad. Según parece, la existencia de otros situados en dicha renta suponía una amenaza para la correcta recepción por parte de las monjas de las cantidades que les correspondían, quienes además no disponían de una carta de privilegio que lo certificara, razón por la cual, el rey conminaba a los responsables de su recaudación a que acudieran primero a las monjas antes que a ningún otro beneficiario de la renta, ya que cuando las cantidades de maravedíes recaudadas no alcanzaban a suplir todos los situados existentes, eran las monjas las perjudicadas por dicha situación ${ }^{73}$.

\section{6}

\section{Concejos y conventos}

Llegados a este punto, podemos valorar como positiva la postura mostrada por los concejos de Zamora y Benavente ante la fundación y posterior asentamiento de los conventos de la Orden de Predicadores en dichos núcleos urbanos.

No podemos olvidar que los siglos XII y XIII supusieron una época de afianzamiento de los contextos urbanos, realidad que fue fruto de una política promocionada por la propia monarquí $a^{74}$. En este sentido, el asentamiento de un convento mendicante contribuía a reafirmar la entidad urbana de un núcleo de población ${ }^{75}$, ya que su presencia en un enclave concreto implicaba necesariamente unas características urbanas que debían asegurar el sostenimiento material de los frailes. Dicha realidad era especialmente aplicable en el caso de la Orden de Predicadores, cuya distribución urbana siempre fue más selectiva que la de la Orden de Frailes Menores ${ }^{7}$. Por otro lado, conviene incidir en los

73 AMDZ, Privilegio del rey don Enrique, s/cl. 1467, agosto, 12. Segovia.

74 La misma Benavente fue fruto de una estrategia de repoblación de «villas nuevas» llevada a cabo en los territorios comprendidos al norte del reino de León por Fernando II en la segunda mitad del siglo XII. Sobre estas cuestiones puede consultarse, por ejemplo: MARTínez Sopena, Pascual. «Espacios y poderes: las villas nuevas reales al norte del Duero». En El Reino de León en la época de las Cortes de Benavente. Benavente: Centro de Estudios Benaventanos Ledo del Pozo, 2002, pp. 101-113. Por otro lado, bien conocida es la política emprendida por el rey Alfonso X, con el fin de reforzar el mundo urbano castellano durante el siglo xIII, tendencia proseguida por sus descendientes. Con respecto a este tema, por ejemplo: GonZÁlez JimÉnez, Manuel. Alfonso X (1252-1284). Palencia: Diputación Provincial de Palencia, 1993; GonŹ́Lez Jiménez, Manuel. «Sobre fueros, concejos y política municipal de Alfonso X». En II Congreso de Historia de Albacete. Albacete: Instituto de Estudios Albacetences Don Juan Manuel de la Excma. Diputación de Albacete, 2002. pp. 11-20.

75 Esta misma impresión es detallada por: Freed, The Friars and German Society, pp. $43-48$ y 51; García Serrano, Francisco. Preachers of the City. The Expansion of the Dominican Order in Castile (12171348). New Orleans: University Press of the South, 1997, p. 23.

76 Le GofF, «Ordres mendiants et urbanisation», pp. 936-937; Graña Cid, María del Mar. "Geografía de lo sagrado y creación de conventos». Miscelánea Comillas. Revista de Teología y Ciencias Humanas, 1999, vol. 57, n. ${ }^{\circ} 110$, p. 193; García Serrano, Preachers of the City, pp. 23-24. 
ALICIA ÁLVAREZ RODRÍGUEZ

beneficios espirituales que dichos conventos ofrecían a los núcleos urbanos, ya que los frailes se estaban situando en la vanguardia de la espiritualidad de la época, proveyendo a los habitantes de las ciudades de unos servicios religiosos más actualizados que los que el clero tradicional podía ofrecer.

La utilización de los espacios conventuales como lugares de reunión de los concejos fue una tendencia bastante habitual en la época, también documentada en otros núcleos de población. Poco a poco las comunidades mendicantes fueron alcanzando grandes cotas de prestigio dentro de los contextos urbanos, prestigio que propició un clima de atracción social hacia dichas comunidades. Sin embargo, en el caso de Benavente es posible observar una especial conexión entre el convento de Santo Domingo y el órgano concejil, la cual puede ser explicada por el lugar de ubicación de la comunidad dominica junto al castillo del concejo. Esta localización pudo influir en la elección del convento dominicano para este fin, situado en lo que parece delimitarse como un lugar simbólicamente conectado con el órgano concejil. Dicha relación alcanzó su máxima expresión a través de la función orante que fue protagonizada por la comunidad de frailes en beneficio del concejo de la villa, la cual fue adecuadamente gratificada por el mismo. En este sentido, la exclusiva participación de los frailes dominicos de Benavente en la procesión del Corpus denota una vez más dicha relación, que podemos calificar de preferente, entre ambas instituciones.

A nivel económico los concejos procuraron favorecer la situación de los conventos, efectuando determinados libramientos y limosnas que fueron bien acogidos por las comunidades conventuales. Sin embargo, Manuel Fernando Ladero Quesada documenta cómo, en el caso zamorano, los Reyes Católicos en 1493 debieron advertir al concejo de la ciudad sobre lo inapropiado de otorgar dichos favores a los monasterios a nivel institucional, incidiendo sobre la conveniencia de que los mismos fueran ofrecidos dentro del ámbito de la vida privada de los regidores ${ }^{77}$. Y es que, aunque en el marco del presente trabajo no profundicemos sobre las relaciones personales que se trabaron entre las oligarquías urbanas, las cuales frecuentemente monopolizaban los órganos concejiles, y los conventos, tanto masculinos como femeninos, dicha situación fue una realidad y por lo tanto merecería un estudio aparte que excedería los objetivos del presente trabajo. Sin embargo, supone, indudablemente, un factor más a tener en cuenta ${ }^{78}$.

Los servicios ofrecidos por los conventos dentro del marco urbano, materializados a través de su función como predicadores y educadores, constituyeron, junto con los sacrificios y oraciones -estos últimos protagonizados por los frailes benaventanos-, una actividad beneficiosa para la comunidad cívica. Se trataba de otra de las facetas que formaban parte del ámbito de regulación de la comunidad urbana, dentro de la línea proseguida por los concejos en pos del bien común. En el caso de Benavente la comunidad de frailes desempeñaba una función orante por el bien del concejo, por el bien y la salud de los reyes ${ }^{79}$-recordemos la cesión de la casa que el concejo realizó al convento como

77 Ladero Quesada, La ciudad de Zamora, pp. 251-252.

78 Este enfoque está siendo objeto de estudio en el marco de nuestra tesis doctoral.

79 En 1397, cuando se produjo esta concesión, la villa aún no había sido definitivamente señorializada, aunque había sido entregada por Enrique III a su esposa, Catalina de Lancaster, después de haber permanecido durante veinte ańos bajo el dominio del duque don Fadrique, bastardo de Enrique II: Hernández Vicente, El concejo de Benavente, pp. 66-67. 
ALICIA ÁLVAREZ RODRÍGUEZ

LOS CONCEJOS DE ZAMORA Y BENAVENTE Y SU RELACIÓN CON LOS CONVENTOS DE LA ORDEN DE PREDICADORES DURANTE LOS SIGLOS XIII-XV

agradecimiento, entre otras razones, por las oraciones entonadas por los frailes- y por la conservación del estado de Rodrigo Pimentel:

Otrosý acatando cómo el dicho sennor conde, nuestro sennor, que agora es les ha dado en limosna mill e quinientos maravedíes para que los ayan de su merçet en cada anno en la rrenta del peso de buhonería de la dicha villa pora siempre jamás, por quel dicho prior et frayres que agora son e están en el dicho monesteiro, movidos con buen zelo e de su buena voluntad tomaron e tyenen cargo dezir cada sábado una misa cantada en el monesteiro por las ánimas del sennor conde don Alfonso Pimentel, cuya ánima dios aya, et de los otros sennores condes, sus antesçesores, et por la vida e conservaçión del estado del dicho sennor conde don Rodrigo Pimentel, nuestro sennor ${ }^{80}$.

Observamos, así, cómo la comunidad dominicana contribuía al bienestar y a la salvación de las dos instituciones que se sucedieron en la titularidad de la villa, de cuyo beneficio también se lucró el órgano concejil ${ }^{81}$.

Sin embargo, la relación entre los conventos y los concejos no siempre discurrió por cauces favorables, sino que también se dieron ciertos problemas entre ambas instituciones, la mayoría de las veces motivadas por la fiscalidad. De esta manera, a través de los casos expuestos, podemos observar ciertas reticencias por parte de las comunidades urbanas a la puesta en práctica de los privilegios disfrutados por los conventos, sobre todo en cuanto a la fiscalidad se refiere. La existencia de excusados conventuales, de manera íntegra en el caso de la comunidad femenina de las Dueńas, provocó que en determinados momentos dichas exenciones no fueran respetadas por los recaudadores, como consecuencia de las repercusiones negativas que estas prerrogativas suponían para el resto de la población urbana. En muchos de los casos fue necesaria la intervención

80 AHN, Clero, carp. 3.532, n. ${ }^{\circ} 16.1464$, febrero, 16. Benavente. En realidad, había sido la condesa dońa María de Quiñones la que había otorgado un mes antes los 1.500 maravedíes situados en la renta del peso de buhonería de la villa, con el fin de que los frailes rogaran a Dios por el alma de su esposo, el conde, ya fallecido, la vida de su hijo y la conservación de su estado: AHN, Clero, carp. 3.532, n. ${ }^{\circ} 16$. 1464, enero, 20. Benavente.

81 En esta misma línea, las limosnas libradas por los concejos urbanos a los monasterios han sido interpretadas por Miguel Ángel López Pérez y M. ${ }^{a}$ Cristina Redondo Jarillo, para el caso de Burgos, con un sentido salvífico y como una garantía del bien común y de la honra de la ciudad. Ambos autores conciben esta actividad concejil como un medio a través del cual Burgos podría obtener una recompensa espiritual, al tiempo que se presentaría como una fiel devota. La función orante de los monasterios de la ciudad, con frecuencia encaminada a velar por el bien de los reyes, contribuye a difundir la idea dentro de la comunidad de vecinos de que es necesario velar por la monarquía y por la ciudad misma, actividad de la que el propio concejo se ofrecía como garantía: López Pérez, Miguel Ángel y Redondo Jarillo, María Cristina. «Gastos de representación en Burgos: limosnas, regalos y honras fúnebres: libros de actas municipales (1379-1476)». En GUERRERo Navarrete, Yolanda (coord.). Fiscalidad, sociedad y poder en las ciudades castellanas de la Baja Edad Media. Madrid: Ediciones de la Universidad Autónoma de Madrid, 2006, pp. 154 y 159-164. Igualmente, se puede consultar el trabajo de M. a del Mar Grańa Cid sobre la espiritualidad femenina en el obispado de Córdoba, en el que se manifiesta también la función orante que fue desempeñada por el monasterio de Santa Clara, de fundación regia, por el bien del concejo y de la monarquía. No obstante, surgirían algunos problemas entre el convento y el concejo derivados de la situación de privilegio de las monjas: Graña Cid, María del Mar. Religiosas y ciudades: la espiritualidad femenina en la construcción sociopolitica urbana bajomedieval, (Córdoba, siglos XIII-XVI). Córdoba: Asociación Hispánica de Estudios Franciscanos, 2010, pp. 70, 81-82 y 86. 
ALICIA ÁLVAREZ RODRÍGUEZ

LOS CONCEJOS DE ZAMORA Y BENAVENTE Y SU RELACIÓN CON LOS CONVENTOS DE LA ORDEN DE PREDICADORES DURANTE LOS SIGLOS XIII-XV

regia para proteger los derechos de los conventos, realidad que fue especialmente frecuente en el caso del convento femenino de las Dueñas, de Zamora, la cual debió de enfrentarse a este tipo de problemas de manera reiterada a lo largo de la baja Edad Media. En otros casos, podemos observar cómo la justicia concejil se convirtió finalmente en la garante de los derechos conventuales, como ocurrió en el pleito del convento de Santo Domingo, de Benavente. La existencia de situados, por merced real, no siempre fue respetada dentro de los ámbitos urbanos, actitud que también frecuentemente desembocó en la intervención real.

\section{REFERENCIAS BIBLIOGRÁFICAS}

Arranz Guzmán, Ana. "El tercer estado castellano ante las relaciones realengo-abadengo: siglos XIII-XV». Hispania, 1989, vol. 49, n. ${ }^{\circ} 172$, pp. 443-476.

Asenjo GonzÁlez, María. "Fiestas y celebraciones en las ciudades castellanas de la Baja Edad Media». Edad Media. Revista de Historia, 2013, vol. 14, pp. 35-61.

Aurell, Jaume. "La espiritualidad de los mercaderes medievales y renacentistas». En Lama, Enrique de la; Merino Rodríguez, Marcelo y Lluch-Baixauli, Miguel. Dos mil años de evangelización: Los grandes ciclos evangelizadores. Pamplona: Servicio de Publicaciones de la Universidad de Navarra, 2001, pp. 99-111.

Beceiro Pita, Isabel. "Caballeros y letrados en las casas señoriales zamoranas del siglo XV». En Primer congreso de historia de Zamora. Zamora: Instituto de Estudios Zamoranos Florián de Ocampo, Diputación de Zamora, 1991, p. 82.

Beceiro Pita, Isabel. "La intervención de la autoridad en las celebraciones religiosas: las fiestas de Benavente y su tierra (1434-1525)». Edad Media. Revista de Historia, 2009, vol. 10, pp. 212-213.

Beceiro Pita, Isabel. «Las redes de la oligarquía en los territorios de señorío: las élites de Benavente y su entorno». En El condado de Benavente. Relaciones Hispano-Portuguesas en la Baja Edad Media. Actas del Congreso hispano-luso del VI Centenario del Condado de Benavente. Benavente: Centro de Estudios Benaventanos Ledo del Pozo, 2000, pp. 207-208.

Beceiro Pita, Isabel. El condado de Benavente en el siglo XV. Benavente: Centro de Estudios Benaventanos Ledo del Pozo, 1998.

Bertrand, Paul. «Limitatio, termini, predicatio. Réflexions sur les limites dans les couvents dominicains, entre nord et sud. Autour du dossier documentaire du couvent dominicain de Rodez». En Cahiers de Fanjeaux, 46. Lieux sacrés et espace ecclésial (IXe-XV siècle). Toulouse: Éditions Privat, 2011, pp. 467-468.

Beuchot, Mauricio. Pensamiento filosófico de San Vicente Ferrer. València: Ajuntament de València, 1995.

Canto de la Fuente, Carlos del; Carbajo Martín, Victoriano Antonio y Moreta Velayos, Salustiano. Ordenanzas municipales de Zamora: siglos XV y XVI. Zamora: Diputación Provincial de Zamora, 1991.

Cátedra García, Pedro M. Sermón, sociedad y literatura en la Edad Media: San Vicente Ferrer en Castilla (1411-1412). Valladolid: Junta de Castilla y León, 1994.

Coria Colino, Jesús. «El pleito entre el cabildo y concejo zamoranos de 1278: análisis de la conflictividad jurisdiccional. Concejo, cabildo y rey». En Primer Congreso de Historia de Zamora. Zamora: Instituto de Estudios Zamoranos Florián de Ocampo, Diputación de Zamora, 1991, pp. 285-303. 
ALICIA ÁLVAREZ RODRÍGUEZ

LOS CONCEJOS DE ZAMORA Y BENAVENTE Y SU RELACIÓN CON LOS CONVENTOS DE LA ORDEN DE PREDICADORES DURANTE LOS SIGLOS XIII-XV

DíAz IbÁÑEZ, Jorge. «Monarquía, Iglesia y poder concejil en Zamora durante la baja Edad Media. Análisis tipológico de los conflictos». Anuario del Instituto de Estudios Zamoranos Florián de Ocampo, 2004, vol. 21, pp. 241-253.

Dios De Dios, Salustiano de. «Poder político, derecho e instituciones». En Santonja Gómez, Manuel et ál. Historia de Zamora. De los orígenes al final del medievo. Zamora: Instituto de Estudios Zamoranos Florián de Ocampo, Diputación de Zamora, 1995, pp. 670-671.

Fernández Ruiz, Raquel. Colección diplomática del monasterio de Santo Domingo de Benavente (1228-1390). Benavente: Centro de Estudios Benaventanos Ledo del Pozo, 2000.

Finanzas y fiscalidad municipal. V Congreso de Estudios Medievales. [Ávila]: Fundación SánchezAlbornoz, 1997.

Freed, John B. The Friars and German Society in the Thirteenth Century. Cambridge: Mediaeval Academy of America, 1977.

García Serrano, Francisco. "Del convento al palacio: los frailes y las oligarquías castellanas (siglos XIII-XIV)». En Beceiro PIta, Isabel (dir.). Poder, piedad y devoción. Castilla y su entorno. Siglos XII-XV. Madrid: Sílex, 2014, pp. 77-102.

García Serrano, Francisco. "The Mendicants as a Mediterranean Phenomenon». En Chubb, Taryn E. L. y Kelley, Emily D. (eds.). Mendicants and Merchants in the Medieval Mediterranean. Leiden: Brill, 2013, pp. 272-289.

García Serrano, Francisco. Preachers of the City. The Expansion of the Dominican Order in Castile (1217-1348). New Orleans: University Press of the South, 1997.

Gelabert, Miguel; Milagro, José María y Garganta, José María. Santo Domingo de Guzmán visto por sus contemporáneos. Madrid: Editorial Católica, 1947.

Goicolea Julián, Francisco Javier. «La influencia de las órdenes mendicantes en la religiosidad de los fieles de la villa de Haro a finales de la Edad Media». En Iglesia Duarte, José Ignacio de la (coord.). Espiritualidad, órdenes mendicantes y franciscanismo en la baja Edad Media. VI Semana de Estudios Medievales de Nájera. Logroño: Instituto de Estudios Riojanos, 1996, pp. 260-261.

GonZÁLEZ JimÉnez, Manuel. «Sobre fueros, concejos y política municipal de Alfonso X». En II Congreso de Historia de Albacete. Albacete: Instituto de Estudios Albacetences Don Juan Manuel de la Excma. Diputación de Albacete, 2002. pp. 11-20.

González Jiménez, Manuel. Alfonso X (1252-1284). Palencia: Diputación Provincial de Palencia, 1993.

González Ramos, José Ignacio. Villas reales en el reino de León. Los procesos pobladores de Fernando II y Alfonso IX en la Tierra de León. León: Centro de Estudios e Investigación San Isidoro, 2008.

González Rodríguez, Rafael. «Notas sobre el llamado "Castillo de Santibáñez" de Benavente». Brigecio. Revista de Estudios de Benavente y sus Tierras, 2004, vol. 14, pp. 69-84.

GraÑa Cid, María del Mar. «Frailes, predicación y caminos en Madrid. Un modelo para estudiar la itinerancia mendicante en la Edad Media». En Segura Graíño, Cristina (ed.). Caminos y caminantes por las tierras de Madrid. Madrid: Asociación Cultural Al-Mudayna, 1994, pp. 300-301.

Graña Cid, María del Mar. "Geografía de lo sagrado y creación de conventos». Miscelánea Comillas. Revista de Teología y Ciencias Humanas, 1999, vol. 57, n. ${ }^{\circ}$ 110, pp. 169-196.

Graña Cid, María del Mar. Religiosas y ciudades: la espiritualidad femenina en la construcción sociopolítica urbana bajomedieval, (Córdoba, siglos XIII-XVI). Córdoba: Asociación Hispánica de Estudios Franciscanos, 2010.

Hernández Vicente, Severiano. El concejo de Benavente en el siglo XV. Zamora: Instituto de Estudios Zamoranos Florián de Ocampo, 1986. 
ALICIA ÁLVAREZ RODRÍGUEZ

LOS CONCEJOS DE ZAMORA Y BENAVENTE Y SU RELACIÓN CON LOS CONVENTOS

Ladero Quesada, Manuel Fernando. «Zamora, formulación y dinámica del poder en un concejo medieval». Medievalismo. Boletín de la Sociedad Española de Estudios Medievales. 1996, vol. 6, pp. 150-152.

Ladero Quesada, Manuel Fernando. La ciudad de Zamora en la época de los Reyes Católicos. Economía y gobierno. Zamora: Instituto de Estudios Zamoranos Florián de Ocampo, Diputación de Zamora, 1991.

Ladero Quesada, Manuel Fernando. Libros de acuerdos del Consistorio de la ciudad de Zamora (1500-1504). Zamora: Excelentísimo Ayuntamiento de Zamora, UNED, 2000.

Ladero Quesada, Miguel Ángel. Fiscalidad y poder real en Castilla. Madrid: Editorial Complutense, 1993.

Le Goff, Jacques. «Apostolat mendiant et fait urbain dans la France médiévale: L'implantation des ordres mendiants. Programme-questionnaire pour une enquête». Annales. Economies, Sociétés, Civilisations, 1968, vol. 23, pp. 335-348.

Le Goff, Jacques. «Ordres mendiants et urbanisation dans la France médiévale. Etat de l'enquete». Annales. Economies, Sociétés, Civilisations, 1970, vol. 25, pp. 924-946.

Little, Lester K. Pobreza voluntaria y economía de beneficio. Barcelona: Taurus, 1983, pp. 215-227.

López Pérez, Miguel Ángel y Redondo Jarillo, María Cristina. «Gastos de representación en Burgos: limosnas, regalos y honras fúnebres: libros de actas municipales (1379-1476)». En Guerrero Navarrete, Yolanda (coord.). Fiscalidad, sociedad y poder en las ciudades castellanas de la Baja Edad Media. Madrid: Ediciones de la Universidad Autónoma de Madrid, 2006, pp. 151-202.

López, Juan, Tercera parte de la Historia general de Sancto Domingo y de su Orden de Predicadores. Valladolid: por Francisco Fernandez de Cordoua y a su costa, 1613.

Maceda Cortés, María Luisa. «El concejo de Benavente de los siglos XiI al xiv». En la España medieval, 1984, vol. 4, pp. 565-594.

Martin, Hervé. «La prédication comme travail reconnu et rétribué à la fin du Moyen Âge». En Hamesse, Jacqueline y Muaille-Samaran, Colette (eds.). Le travail au Moyen Âge. Une approche interdisciplinaire. Actes du Colloque international de Louvain-la-Neuve. Louvain-laNeuve: Université Catholique de Louvain, 1990, pp. 396-400.

Martin, Hervé. Le metier de prédicateur à la fin du Moyen Âge (1350-1520). Paris: Éditions du Cerf, 2007.

Martínez Sopena, Pascual. «Espacios y poderes: las villas nuevas reales al norte del Duero». En $E l$ Reino de León en la época de las Cortes de Benavente. Benavente: Centro de Estudios Benaventanos Ledo del Pozo, 2002, pp. 101-113.

Martínez Sopena, Pascual; Aguado Seisdedos, Vidal y González Rodríguez, Rafael. Privilegios reales de la villa de Benavente (s. XII-XIV). Benavente: Centro de Estudios Benaventanos Ledo del Pozo, 1996.

Medrano, Manuel José. Historia de la Provincia de España de la Orden de Predicadores. Primera Parte. Progresos de sus fundaciones y vidas de los ilustres hijos, que la ennoblecieron, desde la muerte de su Glorioso Patriarcha, hasta el año de M.CCC. Tomo Segundo. Desde el año de M.C.C.XXI. hasta el fin del siglo XIII. Madrid: por los Herederos de Antonio Gonçalez de Reyes, 1727.

Mira, Joan F. San Vicente Ferrer: vida y leyenda de un predicador. Alzira: Algar, 2002.

Miura Andrades, José María. «Las fundaciones de la Orden de Predicadores en el reino de Córdoba. I». Archivo Dominicano, 1988, vol. 9, pp. 343-345.

Miura Andrades, José María. «Las fundaciones dominicas en Andalucía. 1263-1591». En Actas del I Congreso internacional sobre los dominicos y el Nuevo Mundo. Madrid: Deimos, 1988, pp. 78-83. 
ALICIA ÁLVAREZ RODRÍGUEZ

LOS CONCEJOS DE ZAMORA Y BENAVENTE Y SU RELACIÓN CON LOS CONVENTOS DE LA ORDEN DE PREDICADORES DURANTE LOS SIGLOS XIII-XV

Miura Andrades, José María. Frailes, monjas y conventos. Las órdenes mendicantes y la sociedad sevillana bajomedieval. Sevilla: Diputación de Sevilla, 1998, pp. 88-117.

NiEto Soria, José Manuel. «Abadengo episcopal y realengo en tiempos de Alfonso XI de Castilla». En la España medieval, 1984, vol. 4, pp. 707-734.

Rebordinos Hernando, Francisco José. La cátedra de gramática de Benavente (1589-1845). Benavente: Ayuntamiento de Benavente, 2010.

Rojo Alique, Francisco Javier. «El convento de San Francisco de Valladolid en la Edad Media (h. 1220-1518). Vida en el convento y proyección social». Archivo Ibero-Americano, 2006, vol. 66, n.o 255 , pp. 511-519.

RuCQuoI, Adeline. «La réforme monastique en Castille au Xve siècle: une affaire sociale». En DuBOIs, Henri y Vauchez, André. Horizons marins, itinéraires spirituels. Hommage au professeur Michel Mollat. Paris: Publications de la Sorbonne, 1987, vol. 1, pp. 243-246.

SÁnchez Rodríguez, Marciano. Tumbo Blanco de Zamora. Salamanca: [s. n.], 1985.

Vicaire, Marie Humbert. «Le développement de la Province Dominicaine de Provence (12151295)». Annales. Economies, Sociétés, Civilisations, 1973, vol. 28, n. ${ }^{\circ} 4$, p. 1019.

Vicaire, Marie-Humbert. Historia de Santo Domingo. Barcelona: Juan Flors, 1964.

VIVEs I ToRo, Eduard. «Els frares menors a les Terres de l'Ebre: el convent de Tortosa (segles XIIIXIV)». Recerca, 2003, vol. 7, pp. 231-263.

Volti, Panayota. Les couvents des ordres mendiants et leur environement à la fin du Moyen Âge. Le nord de la France et les anciens Pays-Bas méridonaux. Paris: CNRS Éditions, 2003. 
